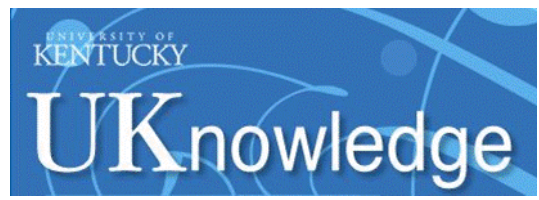

University of Kentucky

UKnowledge

Biosystems and Agricultural Engineering Faculty Publications

\title{
Using Wii Technology and Experiential Learning to Teach Newtonian Mechanics to Rural Middle School Students
}

\author{
Joseph S. Dvorak \\ University of Kentucky, joe.dvorak@uky.edu \\ Tanya C. Franke-Dvorak \\ University of Kentucky, tanya.franke-dvorak@uky.edu \\ Shane Neel \\ Wamego Middle School
}

Follow this and additional works at: https://uknowledge.uky.edu/bae_facpub

Part of the Bioresource and Agricultural Engineering Commons, Educational Methods Commons, Engineering Education Commons, Junior High, Intermediate, Middle School Education and Teaching Commons, and the Science and Technology Studies Commons

Right click to open a feedback form in a new tab to let us know how this document benefits you.

\section{Repository Citation}

Dvorak, Joseph S.; Franke-Dvorak, Tanya C.; and Neel, Shane, "Using Wii Technology and Experiential Learning to Teach Newtonian Mechanics to Rural Middle School Students" (2016). Biosystems and Agricultural Engineering Faculty Publications. 45.

https://uknowledge.uky.edu/bae_facpub/45

This Article is brought to you for free and open access by the Biosystems and Agricultural Engineering at UKnowledge. It has been accepted for inclusion in Biosystems and Agricultural Engineering Faculty Publications by an authorized administrator of UKnowledge. For more information, please contact UKnowledge@lsv.uky.edu. 


\section{Using Wii Technology and Experiential Learning to Teach Newtonian Mechanics to Rural Middle School Students}

\section{Digital Object Identifier (DOI)}

https://doi.org/10.13031/trans.59.11349

\section{Notes/Citation Information}

Published in Transactions of the ASABE, v. 59, issue 2, p. 387-395.

(C) 2016 American Society of Agricultural and Biological Engineers

The copyright holder has granted the permission for posting the article here. 


\title{
USING WII TECHNOLOGY AND EXPERIENTIAL LEARNING TO TEACH NEWTONIAN MECHANICS TO RURAL MIDDLE SCHOOL STUDENTS
}

\author{
J. S. Dvorak, T. C. Franke-Dvorak, S. Neel
}

\begin{abstract}
This study looked at the effects of an experiential learning activity using the accelerometer in the Wii Remote to teach basic concepts of Newtonian mechanics, e.g., acceleration, to middle school students in a rural school district. A major prerequisite for students at the mid-level in biosystems engineering programs is that they have a good knowledge of basic science, including physics. Education in these concepts must begin before college, such as at the middle school level. Improvements in science education are vitally necessary to achieve essential learning outcomes for middle school students in the U.S. and to prepare these students for college and STEM careers. The experiential learning activity evaluated in this study used hands-on experiments involving Wii Remotes in conjunction with a classroom lesson to teach basic concepts of Newtonian mechanics: acceleration, gravity, force, velocity, friction, speed, and motion. This activity used readily available equipment and was integrated into the classroom curriculum so that it has been possible to continue the activity every year without further support from the program that sponsored this study. The specific objective of this study was to evaluate the efficacy of this experiential learning activity with regard to learning outcomes and interest generated in science and engineering. Ninety-two percent (92\%) of the students improved their knowledge from pre-test to post-test during the activity. When the students were surveyed about the activity, the kinesthetic/hands-on aspects of the project were the parts they liked most. Fifty-four percent (54\%) of the students also indicated that the activity made them more interested in science and engineering. The positive outcomes from the activity combined with the readily available equipment make similar activities an excellent option for biosystems and agricultural engineering departments looking for outreach opportunities at the middle school level. This study showed that experiential learning, in middle school science classes, is significant in increasing students' knowledge of acceleration and interest in science and engineering.
\end{abstract}

Keywords. Accelerometer, Experiential learning, Pre-engineering education, Secondary education, Sensors, Wii Remote.

$\mathrm{T}$ This study looked at the effects of an experiential learning activity using the accelerometer in the Wii Remote to teach basic concepts of Newtonian mechanics, e.g., acceleration, to middle school students. All biosystems and biological engineering programs in the U.S. require classes covering basic Newtonian mechanics (Kaleita and Raman, 2012). The European Union has similarly noted the importance of mechanics by defining it as a fundamental basis of biosystems engineering and has stressed the topic even more by including dynamics as part of the fundamental competency in biosystems engineering (Briassoulis et al., 2014). According to

Submitted for review in May 2015 as manuscript number EOPD 11349; approved for publication by the Education, Outreach, \& Professional Development Community of ASABE in November 2015. Preliminary results were presented as an oral presentation, "Utilizing Wii Technology to Teach Acceleration," at the ASABE Annual International Meeting in Kansas City, Missouri in 2013.

The authors are Joseph S. Dvorak, ASABE Member, Assistant Professor, Department of Biosystems and Agricultural Engineering, University of Kentucky, Lexington, Kentucky, Tanya C. FrankeDvorak, Lecturer and Extension Specialist, Department of Community and Leadership Development, University of Kentucky, Lexington, Kentucky; Shane Neel, Science Teacher, Wamego Middle School, Wamego, Kansas. Corresponding author: Joseph S. Dvorak, 128 C.E. Barnhart Building, University of Kentucky, Lexington, KY 40546-0276; phone: 859-257-5658; e-mail: joe.dvorak@uky.edu.
Briassoulis et al. (2014), a major prerequisite for students at the mid-level in biosystems engineering programs is that they have a good knowledge of basic science, including physics. A dynamics course was also required by $62 \%$ of U.S. programs (Kaleita and Raman, 2012). Unfortunately, according to Viennot (1979), students in physics courses from the last year of secondary education through the third year of university education are naturally susceptible to misunderstandings of basic Newtonian mechanics. Trowbridge and McDermott (1981) discovered that correcting these misunderstandings takes an extended amount of time and, if delayed until a university-level introductory physics course, requires covering significantly less material in that course. Thus, learning the core concepts of Newtonian mechanics and motion, which form the basis of engineering statics and dynamics, must begin before university freshman-level physics classes, or engineering students will be less well prepared as they enter the engineering sciences. Therefore, it is vital to consider the teaching of these concepts at earlier stages, such as in middle school.

This project was performed by biological and agricultural engineers as part of a National Science Foundation GK12 Program to enrich learning in K-12 classes and hopefully better prepare and increase K-12 students' interest in biological and agricultural engineering. The project used 
readily available equipment and required little setup, which has enabled the activity to continue every year even after the GK-12 Program involvement ended. The activity described here could be suitable for outreach efforts by many engineering departments.

Middle school is an important developmental period in which to introduce students to topics and career possibilities in science and engineering. Zarske et al. (2012) performed a longitudinal assessment of the impacts of introducing engineering topics before college and documented that the introduction of engineering topics had a long-term impact on students' perceptions. Turner and Lapan (2005) highlighted the effects of interventions in increasing nontraditional career interests (including engineering in their study) among different groups of students at the middle school level and found that these interventions were especially effective at improving students' interest levels. The Virginia Middle School Engineering Education Initiative aimed at producing lessons for integration into middle school classrooms. Researchers found that these lessons were well received by teachers and had a significant positive impact on student education (Richards et al., 2007). A study of the effects of the Future Cities Project at the middle school level found increases in understanding of engineering and improvements in students' attitudes about engineering as a result of participating (McCue and James, 2008). Liang et al. (2015) highlighted the need for biosystems engineers to participate in middle and secondary school outreach efforts. Their study showed significant interest among both middle school and high school students in engineering topics that could be applied to biosensors. It also demonstrated educational impacts from a lesson exposing students to biosensors.

The educational activity performed in this project, the Wii Remote acceleration lesson, was a hands-on learning experience in which students launched a toy car that held a Wii Remote. This activity allowed students to explore and learn about the physics topics of acceleration, gravity, force, velocity, friction, speed, and motion. Several other recent studies have demonstrated the educational impact of hands-on learning to improve understanding of science and engineering topics. Gorlewicz et al. (2014) used a haptic paddle to enhance learning in a systems dynamics class. They documented the use of the haptic paddle, and through their evaluations they were able to conclude that such activities significantly increased student performance on conceptual quizzes. Although Gorlewicz et al. (2014) focused on college students, similar improvements in outcomes were noted in middle school students. The SENSE IT Program taught engineering and science concepts to middle school students through the design, construction, and deployment of water quality sensors (Hotaling et al., 2012). Model wind turbine design was used as a hands-on activity by Cogger and Miley (2012), who also documented improvements in student understanding of science and engineering topics. A project called Studio STEM that used a curriculum from Save the Penguins (Richards et al., 2002) also found improvements in student learning at the middle school level through the use of experiential learning (Schnittka et al., 2012). Furthermore, these projects at the middle school level documented an increased interest in science and engineering among the students who participated. However, most of these projects required the construction of special equipment or implementation of a larger program. These requirements are practical at the college level and might be practical in large school districts with specialized classes and teachers, but they often pose a problem in most secondary schools (Gorlewicz et al., 2014). In contrast, the project in our study used readily available Wii Remotes and other common toys, required very little setup, and was easy to integrate with the standard curriculum. These features also make it suitable for use as a stand-alone outreach effort by university engineering departments.

Many engineering educators have focused on improving students' understanding of the basic physics of motion as a method to improve engineering (Cowan et al., 2003; Fang et al., 2013). Researchers have pointed out that students' misconceptions of the relationship $F=m a$ have been a fundamental impediment to their adequate grasp of the basics of mechanics (Champagne et al., 1980; Clement, 1983). Much of this work has called for the creation of computer models in which different scenarios can be played out so that students can visualize the effects of acceleration (Champagne et al., 1980; Fang et al., 2013). Fang et al. (2013) focused on a computer simulation to aid instruction and concluded that, while the simulation produced learning gains in the students, more educational efforts need to be made to further improve students' understanding of these foundational concepts. Unfortunately, abstract topics such as acceleration have been difficult to teach because of a lack of hands-on activities that enable direct manipulation of acceleration (Hake, 1998). However, recent advances in accelerometers have resulted in widespread availability of devices that provide acceleration values. Rather than requiring students to work through mathematical calculations to gain insight into how acceleration operates, these devices provide instant feedback. This method has been recognized within the education literature as tangible learning, and experiments have been performed to determine how this interaction maps to cognition (Sheridan et al., 2009). Although low-cost accelerometers inside standard integrated circuit (IC) packages were rare just ten years ago, they are now found in numerous consumer devices. The Wii Remote was one of the first such devices to see widespread use (it was introduced six months before the original iPhone). Such devices, including the Wii Remote, have enabled the development of experiential activities that focus on improving students' understanding of acceleration.

Many researchers have discussed the applicability of the Wii Remote to education at all levels. The Wii Remote has been used in freshmen engineering courses to broaden students' interest in computer programming (Brindza et al., 2009) and to improve presentations by university lecturers (Holzinger et al., 2010). Walsh (2009) highlighted the ability of the Wii Remote to better engage kinesthetic learners and those with certain learning disabilities. Wii Remotes have been investigated at the preschool level for development of motor skills (Drell et al., 2010), in music education for teaching rhythm (De Bruyn et al., 2008), and in physical education (Staiano and Calvert, 2011; Vernadakis et al., 
2012). Wheeler (2011), Ochoa et al. (2011), and Erickson et al. (2013) all discussed implementation of the Wii Remote for physics experiments in education. Wheeler (2010) provided the software interface used by the students. Price et al. (2010) discussed the importance of tangible learning in improving education and described how the characteristics of the Wii Remote specifically facilitate this type of learning. Stanford's Wii Science project used the sensors in the Wii Remote to support science education in primary schools and illustrated how Wii Remotes could be used for early science education (Holmquist et al., 2010). All of these projects provide excellent information about why and how to use Wii Remotes in education; however, they do not provide much evidence on the effectiveness of the device for teaching physics topics. The most concrete reported results were qualitative and were based on conversation snippets recorded during a Wii Science project (Ju et al., 2012; Lewis and Ju, 2013). In contrast, our study includes pre- and post-tests of student knowledge and a survey of students' interest in this type of learning. The limited results reported for previous studies were also for more extensive design-based activities. In our project, the entire activity requires no more than a few hours, which makes it easier to integrate into the classroom or to use as a short stand-alone event that could be used in outreach efforts.

\section{Program BaCkground}

The National Science Foundation's (NSF) Graduate STEM Fellows in K-12 Education (GK-12) program provided unique opportunities for graduate students to interact with K-12 students, teach lessons, and introduce lessons on current STEM topics (AAAS, 2013). Although most GK12 programs were based on science topics, Kansas State University's GK-12 program, Infusing System Design and Sensor Technology in Education (INSIGHT), paired graduate students in biological and agricultural engineering and computer science with K-12 teachers to integrate engineering and sensor research into K-12 classrooms (KSU, 2013). As part of the GK-12 program, Wii Remotes were used in a multi-day activity to teach acceleration in a seventh grade science class at a rural public middle school in the Midwest. The entire seventh grade class of 107 students was enrolled in this science class, which was divided into five 50 min sections that met every weekday. All class sections were taught the same content and participated in the same classroom activities. The graduate student and teacher were paired for two years (school years 2010-2011 and 20112012), and the acceleration lesson with the Wii Remotes was taught both years. The GK-12 program focused on outcomes for the participating teachers and graduate students and not directly on the outcomes for K-12 student learning in individual lessons performed as part of the project. Thus, evaluation of K-12 student learning is not generally a part of the GK-12 program but was added for this particular lesson. During the second year, content tests were given before and after the acceleration lesson, and the students filled out a survey after the activity to evaluate their learning outcomes and motivation for learning more about science and engineering. The objective of this study was to evaluate the efficacy of the hands-on acceleration activity taught using Wii Remotes in conjunction with a classroom lesson to help students comprehend the basics of Newtonian mechanics: acceleration, gravity, force, velocity, friction, speed, and motion.

\section{Classroom Activity}

The purpose of the classroom activity was to teach basic physics topics relating to motion. It also provided an opportunity to develop the students' ability to read and interpret graphs of scientific data because the Wii Remote data were presented to the students in real-time in graph form.

\section{ACTIVITY DESCRIPTION}

The first part of the activity was a 10 min lecture that quickly covered the concepts to be learned and the details of how the lab was to be conducted and the equipment to be used. Given the lecture's short duration, it only covered the basic definitions of the terms to be learned and how to interpret the output from the accelerometers in the Wii Remotes. After the lecture, the class was divided into groups of three to five students. Each group was assigned to one of five different stations. All of the stations involved launching a toy car across the classroom using a bungee cord. However, each station measured the travel of the car differently or involved changing a different variable. Figure 1 shows the toy car and launching system used by the students during this activity. To help the vehicles travel straight across the room, they were guided along a strand of fishing line stretched across the room.

Two stations used Wii Remotes to directly record the acceleration experienced by the toy car. At these stations, students adjusted either the launch force or the mass of the car. Based on Newton's Second Law, changing either of these variables should result in a change in the acceleration of the vehicle at the moment of launch. The students tested six different mass amounts and six different force levels. Students recorded the acceleration of the car at launch and either the amount of mass on the car or the force used to

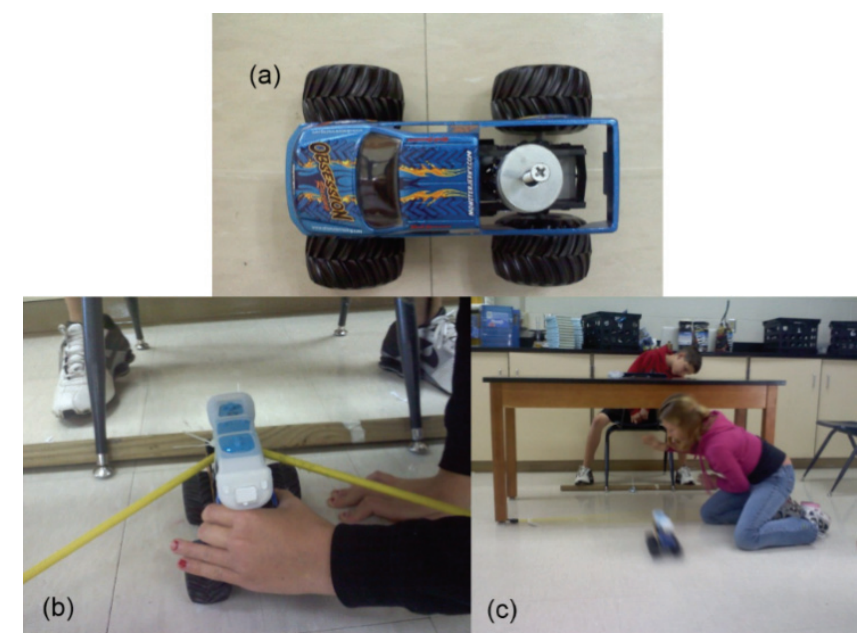

Figure 1. Toy car and launching system: (a) toy car with modifications to carry washers to change car mass, (b) toy car with attached Wii Remote prepared for launch, and (c) toy car immediately after launch. 
launch the car at both stations. To record the acceleration, Wii Remotes were securely attached to the cars, and the acceleration captured by the Wii Remotes was transmitted via Bluetooth to computers running WiiMote Physics version 4.3 (Wheeler, 2010). This program displayed the acceleration data produced by the three-axis accelerometer in the Wii Remote as a continuously updated graph of all three axes. The output from the program was projected onto a whiteboard so that all group members could see the acceleration reported by the Wii Remote in real time.

Figure 2 shows an example of the output produced by WiiMote Physics during the experiments. The students were asked to record the maximum acceleration (in fig. 2, this is the $4 \mathrm{~g}$ spike) at the beginning of the experiment, as this is the acceleration experienced at launch. However, the students also continually watched the output from the Wii Remote to associate different vehicle motions with different acceleration patterns. For example, the students noticed that the vibration of the vehicle caused much low-level variability in acceleration that decreased as the vehicle slowed to a stop (fig. 2 after the initial spike). Other patterns corresponded with a crash of the toy car shortly after launch. Although the students were only asked to record a limited amount of information, the accessibility, immediacy, and interactivity of the data from the accelerometer let them notice other features of acceleration data.

Another two stations were devoted to experiments involving average velocity. As with the acceleration experiments, students varied the car's mass at one station and the launching force at another. Average velocity was determined with the traditional method of using stopwatches and meter sticks to record travel time and distance and then calculate velocity. Figure 3 shows students working at one of the average velocity experiment stations. A final station was dedicated to the effects of friction on the car's travel. While all the experiments for investigating acceleration and average velocity were performed on a smooth tile floor, the friction experiment station was located on a carpeted surface. Except for the change in the surface, the experiment at this station was identical to the force and average velocity

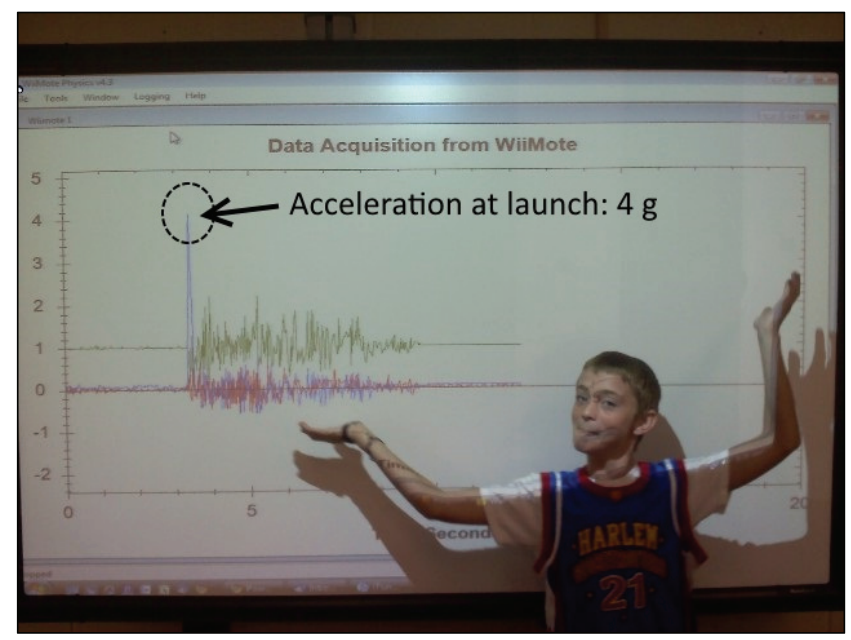

Figure 2. Output (as used by the students) from the WiiMote Physics program showing the acceleration recorded by a Wii Remote during a car launch experiment.

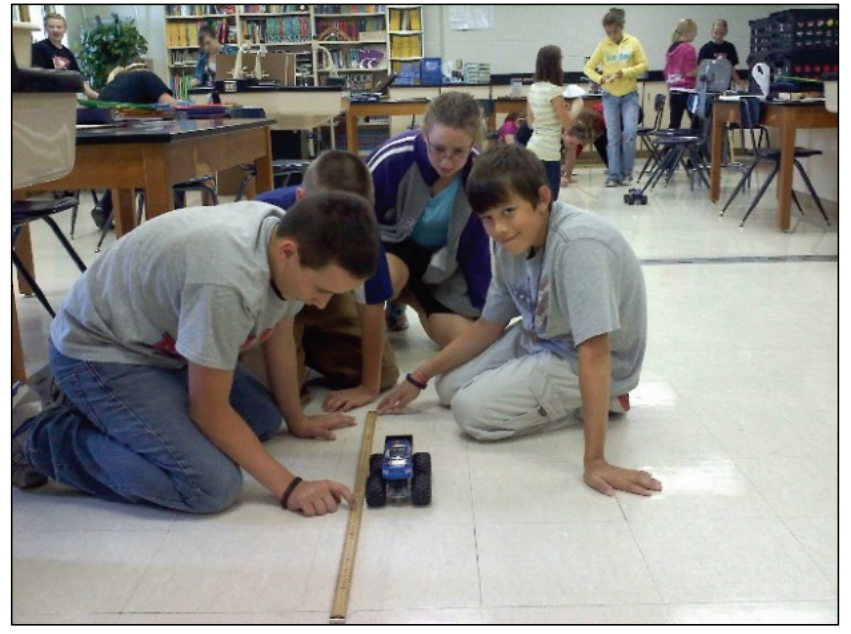

Figure 3. Students at an average velocity experiment station measuring travel distance.

station so that students could compare the friction effects of different surfaces.

The only equipment necessary to complete the activity was Wii Remotes, toy cars, washers and screws to add mass, fishing line, bungee cords, and Bluetooth adaptors for the computers. These supplies were readily available in local stores and were either low cost or could be borrowed and returned (Wii Remotes). Other tools, including stopwatches, measuring sticks, and a basic computer, were available in the classroom and should be available in nearly any science class. The most complicated part of the setup was stretching the fishing line across the room, but this was simple to accomplish immediately before the first class of the day.

The student groups rotated through all five stations so that all students were able to conduct all of the experiments. They were not able to perform all the experiments in a single $50 \mathrm{~min}$ period, so the activity stretched over two consecutive days. The students performed the experiment at each respective station and recorded the value of the variable they were controlling (mass or force) and the output (average velocity or maximum acceleration). At the end of each experiment, they were given four questions asking them to interpret the results:

1. "What is your independent variable, dependent variable, control, and constants for stations 1, 2, 3, 4, and $5 ?$ ?"

2. "Explain your results for each station using the words velocity, acceleration, force, and friction."

3. "Explain the difference between velocity and acceleration."

4. "For what other types of investigations could you use the Wii Remote?"

Although understanding of Newton's Second Law and the ability to relate graphs of velocity and acceleration data were the goals of this activity, the students were not asked to perform calculations and they did not work with any velocity graphs during the activity.

\section{Evaluation Methodology}

The intent of this study was to evaluate the efficacy of 
the described classroom activity. The evaluation was separate from the classroom activity, which was a standard part of the GK-12 program. The evaluation would not normally be performed as a part of the activity but was added as a part of this study. There were two parts in the evaluation. The first was to determine how well the students learned the topics covered by the activity. This was performed by using the pre-test and post-test method. The second part of the evaluation assessed the students' attitudes toward the activity and future interest in science and engineering. As mentioned earlier, middle school is a very important time to build student interest in STEM fields. Therefore, for this activity to be successful, it needed to increase the students' knowledge and skills as well as increase their interest in engineering and the science topics on which engineering is based.

To assess student learning, the students were given a pre-test before the activity and a post-test after the activity. These two tests were identical. The pre-test was given the day before the start of the activity. The post-test was given the day after the activity was completed. The classroom teacher graded these tests and recorded which questions each student answered correctly. For student confidentiality, the teacher used numbers instead of names to identify the students as the results were recorded. The pre- and posttest contained 15 questions, of which 14 were multiple choice. Five questions covered the definitions of acceleration, velocity, speed, friction, and gravity. Three questions covered Newton's Second Law (force equals mass times acceleration), including basic understanding and the ability to perform calculations. Six questions covered the students' ability to interpret graphs of position, velocity, and acceleration over time to understand the conditions that would produce different graphs. The final question asked the students to provide three lists: one list was for similarities between velocity and acceleration, and there was one list each for velocity and acceleration to detail their differences. In grading the tests, one point was given for each correct answer to the multiple choice questions and one point was given for each of the three lists, for a total of 17 points.

Student attitudes and interests were assessed using a survey given right after the students completed the posttest. The survey used a Likert scale to assess student attitudes about the activity and their interest in science and engineering. The Likert scale survey was similar to surveys used in previous research to determine student attitudes and interests (Kelsey et al., 2011). The assessment also contained qualitative questions in which students were able to indicate what they liked most and least about the activity. The responses to these questions were then categorized by the major topic that they addressed. The number of students who mentioned each topic was determined. A single student's response was counted in multiple areas if the response related to multiple topics.

\section{RESULTS}

Students were not required to complete any of the evaluation materials, and class grades were not affected by their answers in any way. Of the 107 students enrolled in the class, 104 students filled out both the pre-test and post-test, and 97 students completed the survey, all of which were voluntary.

\section{Pre-Test and Post-Test}

The identical pre-test and post-test captured key components of the lesson. The mean pre-test score was 7.55 correct answers out of a possible 17 questions (44\%), and the mean post-test score was 12.9 correct answers $(76 \%)$, for an overall improvement of $71 \%$. The nonparametric Wilcoxon signed rank test was used to compare the pre-test and post-test results and showed that the post-test results were significantly greater $(\mathrm{p}<0.05)$. Overall, ninety-two percent $(92 \%)$ of the students improved their score from pre-test to post-test.

Table 1 shows the average scores for each question on the pre-test and post-test and the percent improvement. The pre-test demonstrated the students' understanding of the topics prior to the activity. The pre-test results indicated that friction was the concept with which the students were most familiar (question 4; 86\% correct). Students had more difficulty in identifying the definitions of acceleration (question 1;67\% correct) and speed (question 2;61.5\% correct). The number of correct answers varied for the graph identification questions. For one graph identification question (question 9), only $37 \%$ of students answered correctly. However, for question 11, another graph identification question, $61 \%$ of students answered correctly. Compared to the other questions, the questions on Newton's Second Law (questions 6, 7, and 8) were answered correctly by the fewest numbers of students $(32 \%, 24 \%$ and $20 \%$, respectively).

The post-test results revealed that students had indeed learned the topics in the lesson. Nearly all students were able to identify the definition of friction (question 4; 95\%). They also did extremely well in matching a given situation to acceleration graphs (questions 10 and $11 ; 94 \%$ and $96 \%$, respectively). The only acceleration graph that any students had trouble identifying was that of constant acceleration (question 9), which $73 \%$ of students properly identified. Although a constant acceleration graph is simple, the students did not experience a constant acceleration situation when recording acceleration data during the activity. The multiple choice questions with the largest improvements were those dealing with Newton's Second Law. These were questions 6,7 , and 8 , with improvements of $118 \%, 124 \%$, and $148 \%$, respectively. However, although the scores greatly improved, these questions were still the ones that students were least likely to answer correctly.

\section{StUdent Survey}

The results of the student survey are shown in table 2 . The survey asked questions to discover the students' perceptions of the classroom activity, the classroom teacher, and the graduate student. Questions 1 through 7 were on the front page of the two-sided survey, and $93 \%$ of students answered questions 1, 2, and 4 through 7 . Even though there was a large arrow at the bottom of the first page, indicating to students to continue to the backside of the survey, 
Table 1. Results for individual questions on the pre-test and post-test.

\begin{tabular}{|c|c|c|c|c|}
\hline \multirow{2}{*}{$\begin{array}{l}\text { Question } \\
\text { Topic }\end{array}$} & \multirow{2}{*}{$\begin{array}{c}\text { Test Question } \\
\text { (Question and Answer [from test]) }\end{array}$} & \multicolumn{2}{|c|}{$\begin{array}{l}\text { Percent Correct } \\
(\%)\end{array}$} & \multirow{2}{*}{$\begin{array}{l}\text { Percent } \\
\text { Improvement } \\
(\%)\end{array}$} \\
\hline & & Pre-Test & Post-Test & \\
\hline \multirow{5}{*}{ Definition } & 1. The rate at which velocity changes is called (c) Acceleration [multiple choice]. & 68 & 82 & 20 \\
\hline & 2. The rate at which an object moves (distance/time) is called (a) Speed [multiple choice]. & 62 & 71 & 16 \\
\hline & 3. The speed of an object in a particular direction is called (b) Velocity [multiple choice]. & 43 & 85 & 96 \\
\hline & $\begin{array}{l}\text { 4. A force that opposes motion between two surfaces that are touching is called (b) Friction } \\
\text { [multiple choice]. }\end{array}$ & 86 & 95 & 11 \\
\hline & $\begin{array}{l}\text { 5. A force of attraction between objects that is due to their masses is called (a) Gravity [multi- } \\
\text { ple choice]. }\end{array}$ & 54 & 81 & 50 \\
\hline \multirow{3}{*}{$\begin{array}{l}\text { Newton's } \\
\text { Second } \\
\text { Law }\end{array}$} & $\begin{array}{l}\text { 6. Which of the following would cause the acceleration of an object to decrease? (Students } \\
\text { instructed to consider Newton's Second Law) (c) Decreased force exerted on the object } \\
\text { [multiple choice]. }\end{array}$ & 32 & 69 & 118 \\
\hline & $\begin{array}{l}\text { 7. Which of the following DOES NOT result in an increase in the force (measured in New- } \\
\text { tons) on an object if everything else remains the same? (Students instructed to consider } \\
\text { Newton's Second Law) } \\
\text { (b) Decreased mass [multiple choice]. }\end{array}$ & 24 & 54 & 124 \\
\hline & $\begin{array}{l}\text { 8. What force is necessary to accelerate a } 1,250 \mathrm{~kg} \text { car at a rate of } 40 \mathrm{~m} / \mathrm{s} / \mathrm{s} \text { ? (Students in- } \\
\text { structed to consider Newton's Second Law) (b) } 50,000 \mathrm{~N} \text { [multiple choice]. }\end{array}$ & 20 & 50 & 148 \\
\hline \multirow{3}{*}{$\begin{array}{l}\text { Graph } \\
\text { Identification: } \\
\text { Acceleration }\end{array}$} & $\begin{array}{l}\text { 9. Which graph best illustrates a car maintaining a constant acceleration? Students selected } \\
\text { one of four acceleration/time graphs [multiple choice]. }\end{array}$ & 37 & 73 & 100 \\
\hline & $\begin{array}{l}\text { 10. Which graph best illustrates a car beginning at a constant acceleration, then increasing } \\
\text { acceleration, then constant acceleration, and then decelerating at an abrupt stop? Students } \\
\text { selected one of four acceleration/time graphs [multiple choice]. }\end{array}$ & 53 & 94 & 78 \\
\hline & $\begin{array}{l}\text { 11. Which graph best illustrates a car beginning at a constant acceleration, then increasing } \\
\text { acceleration, and then returning to constant acceleration? Students selected one of four ac- } \\
\text { celeration/time graphs [multiple choice]. }\end{array}$ & 61 & 96 & 59 \\
\hline \multirow{3}{*}{$\begin{array}{l}\text { Graph } \\
\text { Identification: } \\
\text { Velocity }\end{array}$} & $\begin{array}{l}\text { 12. Which graph best illustrates a car with steadily increasing velocity? Students selected one } \\
\text { of four position/time graphs [multiple choice]. }\end{array}$ & 37 & 70 & 92 \\
\hline & $\begin{array}{l}\text { 13. Which graph best illustrates a car beginning at rest, then dramatically increasing velocity, } \\
\text { and then coming to an abrupt stop? Students selected one of four position/time graphs } \\
\text { [multiple choice]. }\end{array}$ & 38 & 69 & 85 \\
\hline & $\begin{array}{l}\text { 14. Which graph best illustrates a car maintaining a constant velocity? Students selected one of } \\
\text { four position/time graphs [multiple choice]. }\end{array}$ & 43 & 78 & 80 \\
\hline \multirow[t]{2}{*}{$\begin{array}{l}\text { Compare and } \\
\text { Contrast }\end{array}$} & $\begin{array}{l}\text { 15. Compare and contrast velocity and acceleration. Use the graphs to help you explain your } \\
\text { answers. Many possible answers [answered with three lists for } 3 \text { possible points]. }\end{array}$ & 33 & 74 & 123 \\
\hline & & $\begin{array}{c}\text { Mean } \\
\text { score: } \\
44 \%\end{array}$ & $\begin{array}{l}\text { Mean } \\
\text { score: } \\
76 \%\end{array}$ & $\begin{array}{l}\text { Overall } \\
\text { improvement: } \\
\quad 71 \%\end{array}$ \\
\hline
\end{tabular}

\section{Table 2. Results of the student survey.}

Question

1. How satisfied are you with the Acceleration Activity using Wii Remotes?

2. How enjoyable was the Acceleration Activity?

3. How satisfied are you with the accuracy of the information provided in the Acceleration Activity?

4. Was the information easy to understand?

5. How satisfied are you with [the science teacher's] responses to questions?

6. How satisfied are you with [the graduate student's] responses to questions?

7. How satisfied are you with [the science teacher's] knowledge level of acceleration?

$\underline{8 .}$ How satisfied are you with [the graduate student's] knowledge level of acceleration?

Questions 9 and 10 allowed students to write in answers. Results are discussed separately.

\begin{tabular}{|c|c|c|c|c|c|}
\hline \multicolumn{5}{|c|}{ Percent Choosing Each Answer (\%) } & \multirow[b]{2}{*}{ 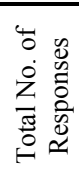 } \\
\hline 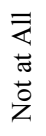 & $\begin{array}{l}\text { Dे } \\
\text { 总 } \\
\stackrel{0}{\bar{\omega}}\end{array}$ & 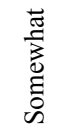 & $\begin{array}{l}\vec{\lambda} \\
\text { in } \\
\sum^{0}\end{array}$ & $\begin{array}{l}\frac{\lambda}{2} \\
\frac{0}{0} \\
\frac{0}{0} \\
0\end{array}$ & \\
\hline 1.0 & 4.1 & 15.5 & 38.1 & 41.2 & 97 \\
\hline 2.1 & 4.1 & 15.5 & 34.0 & 44.3 & 97 \\
\hline 3.1 & 7.3 & 29.2 & 41.7 & 18.8 & 96 \\
\hline 2.1 & 20.6 & 16.5 & 38.1 & 22.7 & 97 \\
\hline 2.1 & 4.1 & 11.3 & 35.1 & 47.4 & 97 \\
\hline 0.0 & 0.0 & 7.2 & 45.4 & 47.4 & 97 \\
\hline 2.1 & 1.0 & 6.2 & 30.9 & 59.8 & 97 \\
\hline 0.0 & 0.0 & 5.5 & 27.5 & 67.0 & 91 \\
\hline
\end{tabular}

\begin{tabular}{|c|c|c|c|c|c|c|}
\hline Question & 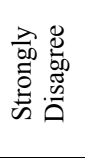 & 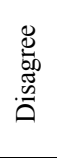 & 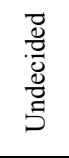 & 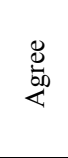 & 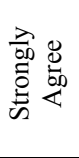 & 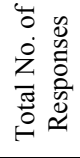 \\
\hline 11. As a result of the Acceleration Activity, I am more interested in science and engineering. & 2.2 & 5.5 & 38.5 & 38.5 & 15.4 & 91 \\
\hline Question & ' & $\stackrel{0}{\infty}$ & $\begin{array}{l}0 \\
\vdots \\
0 \\
0 \\
z\end{array}$ & ż & ' & 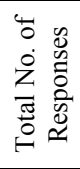 \\
\hline 12. Would you recommend that other students participate in the Acceleration Activity? & & 76.9 & 20.9 & 2.2 & & 91 \\
\hline
\end{tabular}


only $88 \%$ of students responded to the questions on the second page. Eighty-five percent $(85 \%)$ of students responded to the prompt to write in what they liked most, and $86 \%$ indicated what they liked least.

The vast majority of students were either mostly $(38.1 \%)$ or completely (41.2\%) satisfied with the classroom activity and found it either mostly (34.0\%) or completely $(44.3 \%)$ enjoyable. Seventy-seven percent (77\%) of the students said they would recommend the activity to other students. Although by a smaller margin, most of the students found the information either mostly (38.1\%) or completely $(22.7 \%)$ easy to understand. Finally, although the activity only used three days of class time, over half of the students either agreed (38.5\%) or strongly agreed $(15.4 \%)$ that they were more interested in science and engineering because of the activity.

Nearly all student responses about what they liked most were easily divided into four categories. The most common response, given by 45 students, was that they liked the kinesthetic aspects of the project. This category included responses about playing with, using, launching, and crashing the toy cars, as well as general comments about it being hands-on or experiential (Dewey, 1938; Kolb, 1984). Another 20 students listed "getting to use Wii Remotes" as their favorite part, and 11 students just mentioned that it was fun. Finally, ten students most liked being able to see the instantaneous acceleration during the experiment.

The responses for the least liked part of the activity were more varied and could not be categorized into just a few groups. The most common response, listed by 14 students, was "nothing." A similar response of "I don't know" was given by another five students. The most common response that addressed the actual activity (given by ten students) had to do with the time limitation. Ten students also mentioned filling out the pre-test, post-test, or survey as their least favorite part of the activity. Eight students mentioned issues with figuring out the graphs or charts.

\section{DISCUSSION}

The results from the pre-test and post-test confirm that the students did indeed exhibit considerable gains in their understanding of the topics covered by the activity. The definitions of acceleration, speed, velocity, friction, and gravity were already understood by many students, so improvements in the number of students identifying these terms correctly were small, but present. The improvements in the ability to read and understand the graphs were much larger. Nearly all students correctly identified the situations covered by questions 10 and 11 . These situations roughly corresponded to a car being launched (question 11) and a car being launched and crashing (question 10), both of which the students frequently experienced during the activity, which can explain their ability to understand the relatively complex acceleration graphs caused by these situations. The remaining questions dealing with graphs also saw significant improvements in the number of students answering correctly. The heavy use of graphing in displaying data in the acceleration part of the activity appears to have translated into demonstrable improvement in the students' ability to read and interpret graphs.

Some of the largest improvements, based on the pre- and post-test results, were in the understanding of Newton's Second Law. Calculations using Newton's Second Law were not addressed by the activity. Rather than performing calculations, the students directly experienced the effects of Newton's Second Law, so it was encouraging to see that the students were able to develop this understanding through their experience.

The survey results revealed that the students most enjoyed that the activity allowed them to perform hands-on experiments and see the effects of various actions on acceleration, which is in line with the experiential learning theory (Dewey, 1938; Kolb, 1984) and illustrates tangible learning (Price et al., 2008). Before this activity, acceleration was an abstract concept for these students. According to the sixth and seventh grade science teachers of these students (personal communication, 24 September 2010), when the students had previously worked with acceleration, it was always the result of calculations performed using prerecorded or even arbitrary numbers. The hands-on experience of the activity prior to performing calculations appeared to enhance their abilities with the calculations. Although not directly recorded during the project, students tried many different tests with the Wii Remote during the activity. They were constantly questioning why certain features showed up in the real-time acceleration graphs. These features ranged from variations in acceleration caused by a wobbly wheel to spikes in acceleration in different axes when the car crashed or flipped. This ability to experience a formerly abstract concept engaged the students, while the experiments themselves clearly helped the students better understand the concept, which is in agreement with other literature (Cogger and Miley, 2012; Dewey, 1938; Schnittka et al., 2012). The survey results show that the students had a positive attitude toward science and engineering after the experiments. However, attitudes do not directly translate into behaviors that would result in increased learning about science and engineering, much less entering science or engineering fields. Determining how this activity affected these important outcomes will require further work in the form of longitudinal studies.

While the pre-test and post-test evaluation methodology was best suited to the environment available for this study, its use limits the conclusions that can be drawn. As discussed by Marsden and Torgerson (2012), studies involving preand post-tests can only rigorously conclude that an intervention is valuable if added to a curriculum, and not whether it should take the place of other lessons. Therefore, we cannot conclusively state that this activity was a more effective use of three days of class time than traditional lectures or other instructional methods, nor that all teachers should adopt this method. However, as an outreach method that could be offered by visiting engineers or engineering departments, it was clearly an engaging activity and helped students better understand the concept of acceleration. Finally, this activity has had a long-term impact in that the teacher has repeated this activity in subsequent years because of its effectiveness, student engagement, and ease of setup. Future experiments 
will need to be conducted to determine how this activity compares to other classroom activities.

\section{Conclusions}

The Wii Remote provided an excellent tool for this experiential learning activity. The Wii Remote is widely available at a relatively low cost. Children are familiar with the device and associate it with fun activities. Wii Remotes are also durable, as demonstrated in this project by enduring repeated crashes onto the floor without damage. Educators and outreach program specialists could expand the activities presented here to use the even more pervasive and familiar smartphone, although smartphones are generally not as durable, simple, or inexpensive as the Wii Remote. However, with a smartphone, instructors could integrate programming into the activity, using tools such as MIT's App Inventor, to enable students to create their own programs to capture acceleration data, as reported by Dabney et al. (2013). Although the rapid development in consumer electronics means that any particular device may quickly become obsolete, the ubiquitous use of accelerometers in handheld devices appears likely to endure, so future educators and outreach program developers should be able to find suitable devices on which to perform these activities.

This classroom activity increased students' interest in science and engineering and resulted in significant improvements in their understanding of basic Newtonian mechanics. It is hoped that these outcomes will translate into more students selecting engineering majors, and that they will be better prepared for the rigor of engineering classes. This activity was also developed using readily available equipment, requiring little advance setup, to be easier to apply in a rural school that did not offer the specialized classes present in larger schools. Given the high interest in agriculture in rural schools (such as the school in this study), hopefully many of these better prepared and more interested students would enroll in biosystems and agricultural engineering curricula if similar activities were expanded to other rural schools. Determining this type of long-term result would require a longitudinal study, which was not part of this study. However, it can still be concluded that using this activity with Wii Remotes in a Midwest middle school science class helped the students increase their knowledge and understanding of acceleration, friction, and velocity. Ninety-two percent $(92 \%)$ of the students improved their scores from the pre-test to the post-test. Improvements were particularly noted in questions that related directly to the activity, such as identification of acceleration graphs and better understanding of physics terms. Large gains were also noted in the use of Newton's Second Law, which was only indirectly addressed by the activity. Fifty-four percent (54\%) of the students mostly or completely became more interested in science and engineering, while $38.5 \%$ were undecided. These results show that a Wii Remote activity based on experiential learning (Dewey, 1938; Kolb, 1984), in which students have handson experiences and construct their own knowledge, can be applied to a middle school science class to increase student learning and interest in science and engineering.

\section{ACKNOWLEDGEMENTS}

We would like to thank NSF's GK-12 Program for providing the funding (under Grant No. 0948019) for the collaboration that made the activity and this study possible. Author Dvorak received support from this Program as a GK12 Fellow, and author Neel received support as a participating teacher. We would also like to acknowledge Kansas State University's GK-12 program, INSIGHT, for setting up the teacher and graduate student pairing and supporting these activities. Finally, we would like to thank Wamego Middle School for encouraging exploration of new ways to teach various lessons, for support of the study to investigate its effectiveness, and for permission to publish images and information obtained during the study. The experimental plan in this work was submitted to the Institutional Review Board (IRB) Committee on Research Involving Human Subjects for Kansas State University under Proposal No. 6013, and the IRB determined it was exempt from further IRB review with the condition that no changes be made to the procedure.

\section{REFERENCES}

AAAS. (2013). GK-12. Washington, D.C.: American Association for the Advancement of Science. Retrieved from www.gk12.org

Briassoulis, D., Gallego, E., Pantaleo, A. M., Holden, N., Owende, P., Ting, K., \& Mallikarjunan, K. (2014). The "threads" of biosystems engineering. Trans. ASABE, 57(1), 307-330. http://dx.doi.org/10.13031/trans.57.10185

Brindza, J., Szweda, J., Qi, L., Yingxin, J., \& Striegel, A. (2009). WiiLab: Bringing together the Nintendo Wiimote and MATLAB. Proc. 39th IEEE Frontiers Educ. Conf. (pp. 1-6). Piscataway, N.J.: IEEE.

Champagne, A. B., Klopfer, L. E., \& Anderson, J. H. (1980). Factors influencing the learning of classical mechanics. American $J$. Phys., 48(12), 1074-1079. http://dx.doi.org/10.1119/1.12290

Clement, J. (1983). Chapter 14: A conceptual model discussed by Galileo and used intuitively by physics students. In D. Gentner and A. L. Stevens (Eds.), Mental Models (pp. 325-340). New York, N.Y.: Pyschology Press.

Cogger, S. D., \& Miley, D. H. (2012). Model wind turbine design in a project-based middle school engineering curriculum built on state frameworks. Adv. Eng. Educ., 3(2), 1-23.

Cowan, F. S., Usselman, M., Llewellyn, D., \& Gravitt, A. (2003). Utilizing constraint graphs in high school physics. In Proc. 2003 ASEE Annu. Conf. Expo. Washington, D.C.: American Society for Engineering Education. Retrieved from https://peer.asee.org/11470

Dabney, M. H., Dean, B. C., \& Rogers, T. (2013). No sensor left behind: Enriching computing education with mobile devices. In Proc. 44th ACM Tech. Symp. Comput. Sci. Educ. (pp. 627-632). New York, N.Y.: Association for Computing Machinery. http://dx.doi.org/10.1145/2445196.2445378

De Bruyn, L., Leman, M., \& Moelants, D. (2008). Quantifying children's embodiment of musical rhythm in individual and group settings. In Proc. 10th Intl. Conf. Music Perception and Cognition (ICMPC 10).

Dewey, J. (1938). Experience in Education. New York, N.Y.: Macmillan.

Drell, J., Bryant, J. A., \& Akerman, A. (2010). Wee Wii: Preschoolers and motion-based game play. Intl. J. Gaming Comput. Mediated Simul., 2(2), 1-17. 
http://dx.doi.org/10.4018/jgcms.2010040101

Erickson, M., Ochoa, R., \& Ochoa, C. (2013). The Wiimote on the playground. Phys. Teach., 51(5), 272-275. http://dx.doi.org/10.1119/1.4801352

Fang, N., Nielson, K., \& Kawamura, S. (2013). Using computer simulations with a real-world engineering example to improve student learning of high school physics: A case study of K-12 engineering education. Intl. J. Eng. Educ., 29(1), 170-180.

Gorlewicz, J. L., Kratchman, L. B., \& Webster III, R. J. (2014). Haptic paddle enhancements and a formal assessment of student learning in system dynamics. Adv. Eng. Educ., 4(2), 1-31. Retrieved from http://advances.asee.org/?publication=hapticpaddle-enhancements-and-a-formal-assessment-of-studentlearning-in-system-dynamics

Hake, R. R. (1998). Interactive-engagement versus traditional methods: A six-thousand-student survey of mechanics test data for introductory physics courses. American J. Phys., 66(1), 64-74. http://dx.doi.org/10.1119/1.18809

Holmquist, L. E., Ju, W., Jonsson, M., Tholander, J., Ahmet, Z., Sumon, S. I., Acholonu, U., \& Winograd, T. (2010). Wii science: Teaching the laws of nature with physically engaging video game technologies. In Proc. CHI 2010 Workshop: Video Games as Research Instruments. New York, N.Y.: Association for Computing Machinery.

Holzinger, A., Softic, S., Stickel, C., Ebner, M., Debevc, M., \& Hu, B. (2010). Nintendo Wii Remote controller in higher education: Development and evaluation of a demonstrator kit for e-teaching. Comput. Informatics, 29(4), 601-615. Retrieved from www.cai.sk/ojs/index.php/cai/article/view/103/85

Hotaling, L., Lowes, S., Stolkin, R., Lin, P., Bonner, J., Kirkey, W., \& Ojo, T. (2012). SENSE IT: Teaching STEM principles to middle and high school students through the design, construction and deployment of water quality sensors. Adv. Eng. Educ., 3(2), $1-34$.

Ju, W., Acholonu, U., \& Lewis, S. (2012). Using low-cost game controllers to capture data for 6th grade science labs. In Proc. ACM 2012 Conf. Comput. Supported Cooperative Work (pp. 1115-1124). New York, N.Y.: Association for Computing Machinery. http://dx.doi.org/10.1145/2145204.2145370

Kaleita, A. L., \& Raman, D. R. (2012). A rose by any other name: An analysis of agricultural and biological engineering undergraduate curricula. Trans. ASABE, 55(6), 2371-2378. http://dx.doi.org/10.13031/2013.42480

Kelsey, K. D., Lin, H., \& Franke-Dvorak, T. C. (2011). A longitudinal study to determine if wiki work builds community among agricultural adult education students. J. Agric. Educ., 52(2), 71-81.

Kolb, D. A. (1984). Experiential Learning: Experience as the Source of Learning and Development. Englewood Cliffs, N.J.: Prentice Hall.

KSU. (2013). INSIGHT program details. Manhattan, Kans.: Kansas State University. Retrieved from http://gk12.cis.ksu.edu

Lewis, S., \& Ju, W. (2013). Repurposing everyday technologies for math and science inquiry. In Proc. 10th Intl. Conf. Comput. Supported Collaborative Learning. International Society of the Learning Sciences.

Liang, P.-S., Nicolini, A. M., Ogden, K. L., \& Yoon, J.-Y. (2015). Use of biosensors in secondary education classrooms. Trans. ASABE, 58(2), 181-190. http://dx.doi.org/10.13031/trans.58.10631

Marsden, E., \& Torgerson, C. J. (2012). Single group, pre- and posttest research designs: Some methodological concerns. Oxford Rev. Educ., 38(5), 583-616. http://dx.doi.org/10.1080/03054985.2012.731208

McCue, C., \& James, D. (2008). Future cities engineering: Early engineering interventions in the middle grades. Adv. Eng. Educ.,
1(2), 1-24.

Ochoa, R., Rooney, F. G., \& Somers, W. J. (2011). Using the Wiimote in introductory physics experiments. Phys. Teach., 49(1), 16-18. http://dx.doi.org/10.1119/1.3527747

Price, S., Sheridan, J. G., Falcão, T. P., \& Roussos, G. (2008). Towards a framework for investigating tangible environments for learning. Intl. J. Arts Tech., 1(3-4), 351-368. http://dx.doi.org/10.1504/IJART.2008.022367

Price, S., Sheridan, J. G., \& Falcão, T. P. (2010). Action and representation in tangible systems: Implications for design of learning interactions. In Proc. 4th Intl. Conf. Tangible Embedded Embodied Interaction. New York, N.Y.: Association for Computing Machinery. http://dx.doi.org/10.1145/1709886.1709913

Richards, L. G., Laufer, G., \& Humphrey, J. A. C. (2002). Teaching engineering in the middle schools: Virginia middle schools engineering education initiative. In Proc. 32nd ASEE/IEEE Frontiers Educ. Conf. Piscataway, N.J.: IEEE. http://dx.doi.org/10.1109/fie.2002.1157898

Richards, L. G., Hallock, A. K., \& Schnittka, C. G. (2007). Getting them early: Teaching engineering design in middle schools. Intl. J. Eng. Educ., 23(5), 874-883.

Schnittka, C. G., Brandt, C. B., Jones, B. D., \& Evans, M. A. (2012). Informal engineering education after school: Employing the studio model for motivation and identification in stem domains. Adv. Eng. Educ., 3(2), 1-31.

Sheridan, J. G., Price, S., \& Falcão, T. P. (2009). Wii Remotes as tangible exertion interfaces for exploring action-representation relationships. In Proc. Workshop on Whole Body Interaction (CHI 2009). New York, N.Y.: Association for Computing Machinery.

Staiano, A. E., \& Calvert, S. L. (2011). Exergames for physical education courses: Physical, social, and cognitive benefits. Child Devel. Perspect., 5(2), 93-98. http://dx.doi.org/10.1111/j.17508606.2011.00162.x

Trowbridge, D. E., \& McDermott, L. C. (1981). Investigation of student understanding of the concept of acceleration in one dimension. American J. Phys., 49(3), 242-253. http://dx.doi.org/10.1119/1.12525

Turner, S. L., \& Lapan, R. T. (2005). Evaluation of an intervention to increase non-traditional career interests and career-related selfefficacy among middle-school adolescents. J. Vocat. Behav., 66(3), 516-531. http://dx.doi.org/10.1016/j.jvb.2004.02.005

Vernadakis, N., Gioftsidou, A., Antoniou, P., Ioannidis, D., \& Giannousi, M. (2012). The impact of Nintendo Wii to physical education students' balance compared to the traditional approaches. Comput. Educ., 59(2), 196-205. http://dx.doi.org/10.1016/j.compedu.2012.01.003

Viennot, L. (1979). Spontaneous reasoning in elementary dynamics. European J. Sci. Educ., 1(2), 205-221. http://dx.doi.org/10.1080/0140528790010209

Walsh, G. (2009). Wii can do it: Using co-design for creating an instructional game. In Proc. CHI '09 Extended Abstracts on Human Factors Comput. Syst. (pp. 4693-4698). New York, N.Y.: Association for Computing Machinery. http://dx.doi.org/10.1145/1520340.1520722

Wheeler, M. D. (2010). Physics with a WiiMote. WiiMote Physics. Retrieved from http://wiiphysics.site88.net/index.html.

Wheeler, M. D. (2011). Physics experiments with Nintendo Wii controllers. Phys. Educ., 46(1), 57-63. http://dx.doi.org/10.1088/0031-9120/46/1/007

Zarske, M. S., Yowell, J. L., Ringer, H. L., Sullivan, J. F., \& Quiñones, P. A. (2012). The Skyline TEAMS model: A longitudinal look at the impacts of K-12 engineering on perception, preparation and persistence. Adv. Eng. Educ., 3(2), 125. 